\title{
Encontros e Desencontros da Razão Considerações sobre modernidade e pós- modernidade entre Heidegger, Lyotard e Habermas.
}

\author{
Meetings and disagreement of Reason. Appreciation about \\ modernity and post-modernity between Heidegger, Lyotard \\ and Habermas
}

\section{Manoel Ribeiro de Moraes Junior*}

\begin{abstract}
Resumo: Os fins da razão teórica, modernidade, história e da filosofia, foram temas persistentes no palco da filosofia no século XX. Sentido e esgotamento destas expressões sócio intelectuais tinham suas pertinências sobretudo à luz dos impactos existências, econômicos, intelectuais e ambientais consequências dos grandes conflitos bélicos acontecidos entre os séculos XIX e XX. Desconstrução do pensamento foi um imperativo intelectual que ainda ecoa em nossos tempos. Contudo, pode-se perguntar se essa é a única alternativa à prática da filosofia atual. Este artigo reconstrói parte deste debate destacando algumas ideias críticas de Martin Heidegger, Jean-François Lyotard e Jürgen Habermas aos limites $e$ às possibilidades da razão no horizonte contemporâneo de pensamento e sociedade. Assim, apresentase de um lado uma crítica à modernidade no horizonte e, do outro, uma defesa à continuidade da modernidade iluminista.

Palavras-Chaves: Modernidade, Pós-Modernidade, Razão.
\end{abstract}

Abstract: The purpose of theoretical reason, modernity, history and philosophy, were persistent themes in philosophy stage in

\footnotetext{
* Graduação em Filosofia (UERJ) e em Teologia (STBSB). Mestre em Filosofia Política (UERJ) e Doutor em Ciências da Religião (UMESP). Estágio de Pós-Doutorado em Ética e Filosofia Política (UERJ) e Bolsista de Estágio de Pós-Doutorado no CéSoR/EHESS pela CAPES (Proc. 0640-15-8). Problemata: R. Intern. Fil. v.6, n. 3(2015), p 171-197 ISSN 2236-8612 doi:HTTP://dx.doi.org/10.7443/problemata.v6i3.23835
} 
the twentieth century. Direction and depletion of these intellectual expressions partner had their pertinence especially in light of the impacts stocks, economic, intellectual and environmental consequences of major armed conflicts that took place between the nineteenth and twentieth centuries. Deconstruction of thought was an intellectual imperative that still echoes in our times. However, one may wonder if this is the only alternative to the current practice of philosophy. This article reconstructs part of this debate highlighting some critical ideas of Martin Heidegger, Jean-François Lyotard and Habermas to the limits and possibilities of reason in the contemporary horizon of thought and society. Thus, we present the one hand a critique of modernity on the horizon and on the other, a defense to the continuity of Enlightenment modernity.

Keywords: Modernity, Postmodernism, Reason.

\section{Introdução}

Modernidade e Pós-modernidade foram termos supervalorizados na reflexão social no final do século XX e ainda é presente no século XXI. Na esteira desta reflexão reside uma forte preocupação pelo que ainda seja o papel social da razão teórica, pela significação de história e socialização, quais os limites e as possibilidades do pensamento frente às diversidades culturais, etc. O tema foi deflagrado na década na década de 1960 no horizonte da expressão estética e propagouse para as outras áreas do conhecimento, tais como: política, direito, teoria do conhecimento, sociologia, antropologia, etc. Este artigo procura entender a discussão a partir de dois frontes: o da crítica à modernidade e a própria reflexão da pósmodernidade de um lado; do outro, uma leitura sobre a defesa da ideia de que a modernidade ainda está em desdobramento. Neste artigo três autores se destacam: Heiddeger, Lyotard e Habermas. Na primeira parte do artigo, a pós-modernidade será tributada à crítica heideggeriana à razão e à modernidade. O segundo tópico do artigo, se reconstruirá os conceitos chaves propostos por Lyotard a uma idéia de pós-modernidade. Por úlitmo, veremos a posição de Habermas quando ao definhamento do conceito de razão e modernidade frente às mudanças advindas no decorrer do século XX.

\section{De Heidegger aos Pensadores Pós-Modernos}


No período europeu do pós-guerra, este continente passou a viver um clima de reconstrução de valores individuais, sociais, econômicos, políticos, estéticos e outros. Tal momento era decorrente de um progressivo sentimento de repulsa a tudo que mantivesse fortes laços com os ideais iluministas, posto então em suspeita por ter potencialmente deflagrado as fatalidades ocorridas; tais fatos passaram a ser vistos como consequência da forma tirânica e violenta que assumiu a orientação da realidade social, econômica, política e social, pela razão. Surge aí então o criticismo "infausto" dos pensadores frankfurtianos, mostrandose devedor àquela interpretação dada ao processo de modernização nas sociedades ocidentais, subjacente aos interesses teóricos de Max Weber ${ }^{1}$. Para este pensador alemão, a consequência do entranhamento da racionalidade, com respeito a fins no processo civilizatório das sociedades ocidentais, deu-se por uma constante depreciação da racionalidade com respeito a valores; destarte, o resultado deste empreendimento de racionalização foi uma progressiva perda de sentido e liberdade nas esferas cultural e social.

Tendo em vista esta tipologia de orientação weberiana, quanto aos elementos responsáveis pela lógica de desenvolvimento das sociedades ocidentais, a segunda fase teórica destes filósofos alemães é marcada por inscrever os barbarismos do totalitarismo e da opressão como acontecimentos inevitáveis decorrentes deste modelo desencadeado de racionalidade. Segundo Luc Ferry ${ }^{2}$, "desde então, o totalitarismo pareceu situado na mesma via do processo racionalizante (...) E os totalitarismos mais evidentes (Hitler e Stalin) pareciam deste então, para Horkheimer, simples excessos no processo da total racionalização".

Os pensadores do referido instituto, como visto, tornaram nítida a influência do diagnóstico weberiano, ao trabalharem um conceito de razão, sob a égide de uma filosofia negativa da história. Para eles, o processo de esclarecimento trazia consigo uma lógica velada de domínio e repressão, acontecida no decorrer da história humana. O desdobramento histórico deste projeto de razão resultou em um estado social não humanista consequente de um efeito reverso de emancipação social levando assim a um "colapso atual da civilização burguesa". 
Tal repulsa fez surgir, em muitos casos, um nostálgico retorno aos clássicos em depreciação do programa filosófico dos modernos - é marcante, neste contexto, as contribuições filosóficas de Martin Heidegger, Hannah Arendt ${ }^{3}$, Gadamer e outros que, de um modo ou de outro, apresentam as mesmas intuições críticas como estas deflagradas pelos pensadores do chamado instituto de pesquisa social da escola de Frankfurt, porém com derivados filosóficos bastantes diferentes. No entanto, não são poucos os pensadores que veem com bastante suspeita estas atitudes de recusa aos impulsos filosóficos modernos ou, de modo mais amplo, de um retorno nostálgico aos aspectos gerais dos programas filosóficos dos pensadores clássicos. Marcados mais pela recusa e menos por qualquer nostalgismo (até porque é na exaltação da presença do outro, que se tem o ponto sedutor destas filosofias que recusam a tradição para obtenção de uma "verdadeira abertura" para o novo), o pós-estruturalismo (desestruturalismo) francês situa-se numa encruzilhada de caminhos filosóficos (Nietzsche, Heidegger, Wittgenstein - da segunda fase, marcada pela obra Investigações filosóficas -, Bachelard e outros), procurando radicalizar, a todo custo, uma desconstrução de todas e quaisquer pretensões de construção de estruturas universais da razão - denunciando também a caducidade de tal atitude, encarando-a como nociva e incompatível com as característica de uma mundo cada vez mais marcado pelo reconhecimento da diversidade cultural. Derrida, Foucault, Lyotard, Deleuze e o italiano Vattimo, desdobram seus interesses filosóficos (a partir de intuições nietzschianas e heideggerianas) em denúncias àqueles que pretendem soerguer as pretensões tradicionais do discurso "forte" da razão, que desta crítica ferrenha supervalorizam a alteridade e a primazia da experiência estética.

Este debate está recheado de uma heterogeneidade tanto no confronto entre as duas frentes, como também nos confrontos internos; mesmo assim, existem aspectos comuns que mantém uma tênue identidade entre eles. Para os liberais, segundo A. Berten $^{4}$, a liberdade de consciência, o respeito pelos direitos individuais e o receio das formas paternalista de Estado, constituem as expectativas mínimas de identidades entre eles para estes pensadores é necessário que haja uma desoneração por parte do Estado de Direito, da responsabilidade de gerar normas baseadas numa concepção previamente estabelecida do 
bem viver, em favor daquelas que se preocupam em gerar normas justas. A recusa ao formalismo moral em favor de uma ética das virtudes e uma aproximação a concepções políticas vinculada a tradições, seriam traços comum daqueles que são identificados como comunitaristas. Os pós-estruturalistas, deste modo, mantêm uma certa proximidade com os comunitarianos; pois suas considerações sobre a ética, orientadas pela forte ênfase na alteridade e na não comensurabilidade dos jogos de linguagem, marcam uma prioridade temática às questões concernentes ao sistema valorativo ético (inversamente proporcional às questões cognitivo-morais).

A transição do século XIX para o século XX é marcada por uma espécie de espírito reformador que atinge todas as áreas do saber: quer na música com o atonalismo de Schöenberg e Stravinsk ou com o refinamento voluptuoso das composições de Debussy, quer nas ciências da natureza que tornam obsoleta a geometria euclidiana e outros modelos tradicionais de operação científica; e ainda se poderia navegar nos detalhes da literatura, arquitetura, pintura e outras diversas expressões humanas para se ter o momento do espírito intelectual pós-metafísico, o que não é do interesse teórico no momento. Já na área do pensamento filosófico, desde Marx provavelmente, se pensa uma forma de organização do pensar e da prática humana que se desvincule radicalmente da tradição, mesmo que esta ruptura leve a um abandono dos privilégios de um modo específico de reflexão (o filosófico), que respirava outrora os ares pomposos de realeza do saber. Estas reformas e despedidas foram aguçadas tão fortemente, que levaram não só a radicais transformações, como também a severas despedidas.

A filosofia, como toda a expressão cultural do mundo europeu, é marcada por uma avalanche de críticas que marcaram pertinentes tentativas de despedidas - por filósofos que viam a impotência dos seus recursos reflexivos num mundo marcado pelo crescente interesse técnico-científico - em propostas anunciadas que poderiam ser resumidas em uma possível diluição de seu potencial em novas atividades de pensamento (aí temos a radicalização, p. ex., dos pensadores vienenses), ou em atividades políticas que atualizem o potencial emancipador até então recluso a dimensão da reflexão.

O texto O Fim da Filosofia ${ }^{5}$ de Martin Heidegger representa uma nova perspectiva de interesse dentro de sua

Problemata: R. Intern. Fil. v.6, n. 3(2015), p 171-197 ISSN 2236-8612 
própria trajetória intelectual, reformulado após uma fase que teve como marco a publicação da obra Ser e Tempo, e que se enquadra neste momento de pensamento anunciado anteriormente. Segundo Oliveira ${ }^{6}$, "depois da inversão, o fundamento não é mais a constituição ontológica do 'eis-aí-ser', mas a própria verdade do ser. Isto vai mudar todo o sentido da tarefa da filosofia. A mudança é tão radical que Heidegger vai chegar mesmo a não querer mais chamar de filosofia a nova perspectiva aberta ao pensamento".

\section{A Incumensurabilidade dos Jogos de Linguagem Culturais Como Motivos Pós-Modernos de Pensamento.}

A obraO Fim da Filosofia é a inversão do pensamento platônico (inaugurado por Marx) em suas últimas consequências na deflagração da diluição do seu 'todo histórico' na prática do domínio técnico-instrumental do mundo (onde é suspenso a prática teórica de geração e delimitação de sentidos ontológicos às coisas, por uma intervenção racional de representação e cálculo), ou em outras palavras: a sua dissolução nas práticas das ciências particulares de natureza técnica (cibernética). De interesses e influências notoriamente consequentes ao deste filósofo alemão, anteriormente citado, as críticas de Lyotard marcarão novidades no que concerne às críticas do pensamento filosófico de corte moderno. Para ele, aquilo que Kant configurou nos seus escritos críticos e denominado por Weber como "esferas da cultura" (ciência, estética e o normativo-social - direito, enquanto normas institucionais; moral enquanto normas "cognitivo-universais"; e ética, enquanto normas valorativas, culturamente situadas), entraram num momento conhecido por pós-moderno.

O seu "ponto-chave de leitura" parte de uma situação que ele compreende como sendo a crise dos relatos, enquanto metadiscurso que pretende assegurar a legitimidade, tanto da produção das ciências quanto das instituições políticas - já que na modernidade os diversos saberes partiam de um ponto de fundamentação última para obtenção de uma garantia racional: a sua legitimação. As ciências por efeito do seu "progresso", fez desnecessária a importância de uma fundamentação última com isso, Lyotard mostra-se devedor a Heidegger quando 
compreende que o progresso científico não acontece devido à existência de uma instância maior (o que faria recorrer a um conceito obscuro ou metafísico de mundo perfeito das ideias) que lhe garanta tal status (progresso em direção a perfeição), e sim por ter, como pensa Heidegger, consciência da ciência ser uma espécie de inversão e diluição da metafísica na prática lógico e técnico-experimental das investigações teóricas ${ }^{7}$, criando para si uma progressiva autonomização. O saber está voltando para as condições imediatas, tanto na utilidade quanto na sua produção, perdendo seu vínculo de mediação subalterna com um possível "espírito legitimador metafísico". A sua eficácia e extensão estará vinculada tão somente à tecnologia da informação $^{8}$ - voltada ao mercado de conhecimento e ao procedimento que ela mesma lhe impõe.

A condição pós-moderna então é marcada pela diluição das metanarrativas nos diversos jogos de linguagem, quando estes ganham dignidade e alteridadeaté mesmo de não "comensurabilidade" universal. Ela dispensaria a constante busca de estruturação universal da linguagem, denunciando que o processo de legitimação social das instituições de coordenação social orientadas pela categoria da justiça e os da prática científica, sob a categoria da verdade, estão interligadas tão somente pela constante vontade de aperfeiçoamento do sistema vigente de poder. Com a perda "de um metassentido" gerado por uma metarelato, temos a ascensão dos "jogos de linguagem", compreendidos como a autoridade das esferas culturais, das próprias culturas locais, e outros sistemas simbólicos situados em um momento e local quaisquer que sejam. Lyotard utiliza-se de Wittgenstein e de Davidson ${ }^{10}$ para dizer que estes "jogos de linguagem opõe, mutatis mutandis, uma dificuldade análoga ao princípio de uma linguagem homogênea" - isto implica uma tirada de toda pretensão de uma estruturação forte à universalização, que possibilite diálogos consensuais - só é possível a persuasão dirigida por um pretendente a veracidade: não há evidências de uma instância que garanta um reconhecimento comum aos debatedores, de algo universal que os leve a "convicções" da verdade"1.

A sociedade contemporânea, que é marcada por uma fase avançada do capitalismo, deflagrou uma mutação das técnicas e das tecnologias, como também no funcionamento das instituições estatais. Segundo este autor, elas devem desprender- 
se e inverter o seu caminho: ele deve adotar os feixes dos jogos de linguagem como horizonte para as suas orientações na ordem de sua auto-identidade de e funcionalidade, ultrapassando assim, as antigas concepções sobre este sistema de agregação social. A "autopoiesis" funcional destas instituições, deve desmantelar-se em favor da potencialidade dos jogos de linguagem concernidos às suas deliberações. Isso porque a compreensão do Estado como aparelho uniformizador do ambiente social a ele submetido, não é compatível com a emergente situação da sociedade pós-moderna ${ }^{12}$. Esta sociedade, como feixe de jogos de linguagens (heteromorfismos de enunciados ${ }^{13}$ ), não suporta uma "metaprescrição" que pretenda dar conta de todas as suas variantes; segundo o próprio Lyotard,

\begin{abstract}
não existe nenhuma razão de se pensar que se possa determinar metaprescrições comuns a todos estes jogos de linguagem e que um consenso revisável, como aquele que reina por um momento na comunidade científica, possa abarcar o conjunto das metaprescreções que regulam o conjunto dos enunciados que circulam na coletividade ${ }^{14}$.
\end{abstract}

Uma reorientação a um constante reconhecimento da pluralização daquilo que Lyotard insistentemente chama de "jogos de linguagem", tem o propósito ${ }^{15}$ de: 1) evitar qualquer tipo de sufocamento consequente de uma atitude incessante para estabilizar o quadro social (isomorfismo político), e 2) na existência necessária de um consenso, ele deva ser composto pelos concernidos e que o conteúdo motivado por tal proposta, que seja portador de conteúdo flexível para uma possível reformulação que poderá acontecer a qualquer instante. A preocupação, no entanto, é com a existência de uma instituição política que não mais se fixe em dispositivos mínimos de estabilidade, soterrando assim a dinâmica dos feixes plurais dos jogos de linguagem: "pois as disputas serão então constituídas por conhecimentos (ou informações) e a reserva de conhecimento, que é a reserva da língua em enunciados possíveis, são inesgotáveis" 16 .

Tardiamente, confirmado provavelmente em 1993 com o escrito "muro, golfo e sistema" 17 , Lyotard passa a ter consciência de que a própria razão crítica esteja voltada à otimização dos sistemas - o que não implica numa refutação de suas premissas pós-modernas, pelo contrário. Para ele, bem

Problemata: R. Intern. Fil. v.6, n. 3(2015), p 171-197 ISSN 2236-8612 
diferente do que Habermas compreende ${ }^{18}$, o sistema (as instituições de mercado, política e direito, e a racionalidade) tem um status funcional tal como compreende os funcionalistas alemães ${ }^{19}$. A autofuncionalidade do sistema é marcada por um desdobramento indiferente às estruturas sociais, culturais e éticas. O potencial crítico emergido nas sociedades ocidentais foiconsequências de sua abertura que tinha o objetivo de subsistência. Para tanto, Lyotard passa a ver como impotente as inflamadas críticas de corte revolucionária (como aquelas de motivação marxista, que pretendiam a elaboração de alternativas modelares de políticas de agregação, e economia de produção, de distribuição mercantis e de consumo) descobrindo a partir de uma análise das conjunturas históricas presentes, que a crítica que exercia a função emancipadora, continua com tal propósito, mas de maneira defensiva. Defensivo porque o sistema é quem garante abertura, fazendo com que o intelectual passe apontar para os focos que atrofiam a possibilidade de extensão sistêmica (a não assimilação positiva, tanto para o assimilante quanto para o assimilado), deixando espaços para sua recusa e possíveis tensões.

O sistema é compreendido como elemento agregador ${ }^{20}$ com dispositivos de flexibilização receptiva (assimiladora), que não necessita de um sistema legitimador unificante (metafísica, ou qualquer outro programa religioso ou mítico). Isso porque ele torna-se "consciente" que sua impossibilidade de sucesso em todos os seus setores e deliberações, devido às diversidadespluriformais das diversas "coisas" (culturas, sociedades, indivíduos e outros que requerem para si um conjunto simbólico de compreensão do mundo) que podem resisti-lo por motivos de estranhamentos. Ora, sendo assim, a abertura e a opção pelas flexibilizações de suas estruturas, foram opções assumidas por intencionarem a assimilação destas resistências; como isso, ele (o sistema integrado de ações comerciais e políticas) passaria garantir a sua otimização a partir de sua opção numa flexibilidade assimiladora. A crítica emanciapadora apresenta-se então como dispositivos sistêmico, que apontam os espaços falhos que os mecanismos de funcionamento e expansão estão transparecendo, pondo em risco o funcionamento do todo.

Mediante a tanto, a questão ética em Lyotard oferece-nos as seguintes conclusões: 
1. A partir da teoria dos jogos de linguagem de Wittgenstein e da teoria de Davidson, este filósofo francês conclui que a evidência requerida pelo discurso filosófico tradicional que possibilitaria uma estruturação ou fundamentação de um modelo mínimo de universalidade racional, está imersa num discurso particular (envolvido por um jogo simbólico culturalmente situado) que poderia ser entendido, assim, como uma espécie de discurso colonizador;

2. A pretensão de consenso ficaria então reduzida às tentativas de persuasão, que é a prática de convencimento por referências a um sistema valorativo (enquanto sistema éticocultural do falante);

3. O tratamento ético, consequentemente, estaria reduzido ao reconhecimento das alteridades ético-locais, sendo entendida como impossíveis as práticas de construções de pontes racionais para o estabelecimento de comunicação neutra para o estabelecimento de um consenso mínimo entre participantes de culturas e sistemas ético-valorativos distintos.

\section{O Contexto Pós-Metafísico e Pluralidade da Filosofia e Sociedade no Pensamento de Jürgen Habermas}

As abordagens sobre os modelos de razão sempre constituíram um tema fecundo no debate filosófico. Isto porque a racionalidade sempre foi tomada, ao menos no mundo ocidental, como o horizonte legitimador a partir do qual podemos situar nossos empreendimentos científicos, morais e estéticos. Por conseguinte, este debate assumiu várias formas dentre as quais podemos destacar, de maneira ampla, alguns destes momentos: em primeiro lugar, o momento clássico do debate filosófico (período que vai da Grécia Clássica até o fim da Idade Média) no qual o esquema "ontoteológico" demarcou as diversas tentativas de se compreender a razão humana a partir de estruturações normativas que garantissem sua unidade em face do pluralismo dos entes; em segundo lugar, o momento moderno que se caracterizou por tentar compreender a mesma razão humana a partir das operações cognitivas do sujeito, enquanto portador de critérios universais de realização do entendimento possível. 
No século vinte a filosofia apresentou, segundo Habermas ${ }^{21}$, um palco de quatro movimentos filosóficos (fenomenologia, estruturalismo, filosofia analítica e marxismo) que, sendo algo mais queexpressões intelectuais estanques, elas apresentaram-se como fontes de temas fecundos que propiciaram o desenvolvimento de discussões além das expectativas iniciais. Esses quatro movimentos filosóficos autônomos e, no entanto, partes integrantes de uma mesma sinfonia: o pensamento pós-metafísico - constituíram aquilo que Habermas designa como "os impulsos mais importantes do filosofar no século XX"22.

Estes impulsos levaram o filosofar do nosso século a assumir traços peculiares que, consequentemente, fizeram surgir rupturas com a tradição. Para o nosso autor, tais motivos de pensamento seriam os seguintes ${ }^{23}$ : i) o "pensamento pósmetafísico" representa o momento em que a razão passa a ser apoiada em procedimentos, abandonando as reflexões privilegiadas que impõe per se as estruturas da razão que decidem sobre a racionalização do mundo dos homens e da natureza; ii) a "guinada lingüística" impõe-se como deslocamento para um novo paradigma, que tende a superar a tradição filosófica fincada no paradigma da consciência, no momento em que a compreensão da constituição da interação social e a construção do conhecimento sobre os fatos no mundo deixam de ser operações meramente fundadas numa consciência solitária e passam a ser compreendidas através das relações lingüisticamente mediadas; iii) um novo "modo de situar a razão" aparece como tentativa de compreender a racionalidade humana não mais como algo que transcende os contextos das práticas historicamente encarnadas em nossos mundos da vida; iv) e, por último, a "superação do logocentrismo" que surge como tópico complementar do anterior, no qual a idéia de razão passa a ser compreendida se, e somente se, for reconstruída a partir de suas próprias operações, ou seja, das realizações cognitivas que, para Habermas, "estão enraizadas na prática précientíficas que existem entre pessoas e coisas" 24 .

Mediante estes quatro motivos não tradicionais de pensamento, Habermas percebe, entretanto, que as diversas teorias filosóficas têm adotado posturas malogradas ao não conseguirem oferecer alternativas a um pensamento pósmetafísico ${ }^{25}$. Segundo nosso autor, estas posturas filosóficas 
mantém uma relação obscura com a metafísica ao não abdicarem de comportamentos característicos das "cosmovisões fechadas" ${ }^{26}$, razão pela qual o filosofo de Frankfurt partirá para uma análise da metafísica na tentativa de compreender melhor os motivos que levaram a sua total desvalorização.

Para falarmos acerca de um afastamento do modo metafísico de pensar faz-se necessário, antes de tudo, um esclarecimento sobre o próprio pensamento metafísico ${ }^{27}$. Esse pensamento é apresentado por Habermas a partir de algumas referências gerais que o caracterizam até mesmo em sua passagem pelo paradigma da consciência:

1) o pensamento da identidade refere-se ao modo como a filosofia, na Antiguidade, preocupou-se em articular conceitualmente uma unidade na totalidade da realidade garantidora do sentido da multiplicidade dos entes. Tal aspecto tem uma dupla face: lógica e ontológica. Destarte, Habermas mostra que a partir deste híbrido impulso metodológico a filosofia fez emergir o conceito de "uno" - como algo originário (no plano ôntico) e não contraditório (no plano lógico) -, conceito que garantia o equilíbrio, a ordem e a razão de ser de toda uma multiplicidade de particularidades;

2) o idealismo mostra como a reflexão filosófica, fazendo uso do modelo abstrato e dedutivo da geometria, extraiu um princípio não condicionado, um principio primeiro. A partir deste fundamento arquetípico - o Ser -, a filosofia fez derivar as idéiasque formam os entes particulares, garantindo assim a ordem mundana. Metafísica clássica compreendeu a fundamentação última a partir da explicitação de uma lei no cosmo, na natureza ${ }^{28}$. Habermas mostra, então, como a filosofia moderna, fincada no paradigma mentalista, traz consigo toda esta herança da metafísica. Segundo este autor, as filosofias da reflexão (de Descartes a Hegel) comprendem a realização do racional como base numa auto-referênciareflexiva que faz manter, conseqüentemente, o primado da teoria frente à práxis, da identidade frente à diferença. A herança marcante seria, pois, a supremacia totalizadora do "uno"na compreensão dos fatos variantes, unidade constituída a partir de referências no interior das próprias reflexões filosóficas;

3) o conceito forte de teoria representa o fato de que tanto o pensamento clássico como o moderno, da maneira similar às vias salvíficas das grandes religiões, adotaram a idéia de um 
caminho privilegiado na direção de um saber capaz de apreender os fundamentos da realidade, necessariamente situados além dela e somente atingíveis por uma vida especial dedicada à contemplação; com isso são depreciados os contextos nos quais acontece as nossas experiências cotidianas ordinárias.

A partir da deflagração dos quatros motivos de pensamento pós-metafísico as abordagens sobre à razão caíram em aporias que devem ser tomadas como atitudes unilaterais ${ }^{29}$. Para Habermas é necessário, primeiramente, garantir a superação do paradigma da consciência a fim de se observar os desafios levantados pelo esgotamento do pensamento tradicional, sem que se caia numa afastamento das tarefas fundamentais da filosofia, a saber, de guardiã e de interprete da racionalidade $^{30}$. A razão comunicativa mostra-se como uma saída promissora do paradigma da razão centrada no sujeito, trazendo consigo os motivos de pensamento pós-metafísico: "A razão centrada no sujeito", afirma Habermas, "encontra seus critérios em padrões de verdade e sucesso que regulam as relações do sujeito que conhece age com o mundo dos objetos possíveis os dos estados de coisas. Quando, pelo contrário, entendemos o saber como transmitido de forma comunicacional, a racionalidade limita-se à capacidade de participantes responsáveis em interações de se orientarem em relação a exigências de validade que assentam sobre o reconhecimento intersubjetivo" 31 .

Tal conceito comunicativo de razão aparece como tentativa de se pensar uma renovação nos fundamentos normativos da teoria crítica a fim de se resolver a aporia de uma crítica da razão baseada em critérios normativos subjacentes à razão criticada. Adorno e Horkheimer, por exemplo, ao fazerem a crítica da razão instrumental não conseguem um desdobramento eu vá além das dificuldades apontadas; isso acontece pelo fato de que é passível de obscuridade qualquer tentativa de abstração das forças reificante quando ela é conseqüência do modo de reflexão empreendido (que é o uso da filosofia tradicional em vista da sua própria crítica). Daí decorre a inserção de elementos que residem numa espécie de "outro da razão" no intuito de reabilitação de uma razão emancipadora e não reificante ${ }^{32}$.

Para Habermas, a filosofia compreendida segundo uma orientação pragmático-formal ativa um deslocamento 
paradigmático de modo que a razão não seja mais concebidapartir de qualquer reflexão autoreferencial. $\mathrm{O}$ caráter intersubjetivo, mediado pela linguagem, da realização do entendimento possível abandona qualquer privilégio do sujeito solitário e tenta compreender a realização da razão pelo uso da linguagem. Este momento traz consigo a finalidade de estabelecer vínculos voltados para um entendimento mútuo, racionalmente justificado. A realização da razão passa a ser uma idéia reconstruída a partir de estruturas pré-científicas, ou seja, a partir das capacidades que possuem os indivíduos de gerar consensos racionalmente motivados ou discursivamente estabelecidos.

Sendo assim, o consenso é caracterizado como um momento em que única força admitido no debate é a do melhor argumento. Essa formulação de uma razão dialógica, segundo Habermas, segue uma via reconstrutiva que evita todo modelo transcendental que pretenda funcionar como uma via privilegiada de saber. Neste sentido, Habermas se distancia da pragmática transcendental de K.-O Apel ao propor a idéia de uma pragmática universal que conjuga análise formal e análise empírica no interior da abordagem reconstrutiva dos pressupostos universais e incontornáveis da comunicação ${ }^{33}$.

\section{Para Além de uma Crítica Nefasta à Razão teórica}

A noção de razão comunicativa caracteriza-se por sua procedimentação de feitio discursivo. Diferentemente do que havia pensado Horkheimer, ao depreciar a rrazão formal, este modelo de razão é conseqüência de uma descentralização necessária causada pela autonomização das esferas de valor: ciência, moral e estética. Os critérios de validade são seguidos de acordo com as exigências argumentativas das pretensões de verdade, correção e veracidade. A debilidade do conceito habermasiano de razão é explicado por sua inserção na rede lingüística natural do mundo vivido. ${ }^{34}$ Para o filósofo alemão, o conceito de "mundo da vida", fonte das estruturas simbólicas e de suas significações, não deve ser suplantado por uma filosofia substancial. Esse novo modelo de razão tende, portanto, a fomentar a autonomização da esfera comunicativa a fim de se 
evitar qualquer forma de colonização proveniente dos subsistemas econômicos e administrativos.

$\mathrm{Se}$ o conceito de razão comunicativa ergue articulaçõesracionais dos indivíduos no cotidiano, quer no uso cognitivo-instrumental, quer no uso prático-moral, quer ainda no uso estético-expressivo, ele também abre a possibilidade de se evitar um privilégio na escolha de quaisquer destes aspectos, unilateralidade que conduza a um atrofiamento do processo moderno de autonomiazação das esferas axiológicas diferenciadas segundo lógicas próprias e independentes.

O modo mais genérico possível de se referir ao modelo de razão assumido no debate filosófico da modernidade pode ser explicitado por um abandono de posturas tidas como "ingênuas" perante a natureza. Mas o que significou esse abandono? Qual foi a sua relevância para o pensamento ocidental?

A revolução técnico-experimetal, iniciada pela ciência moderna, conferiu à natureza um estatu to de objeto cognoscível. Com isso, os filósofos modernos tiveram que buscar uma outra instância (que não fosse a natureza, como fazia os pensadores clássicos) para que o princípio e limites da razão fossem articulados. Daí surgiu a idéia moderna de um sujeito operante, cognoscente, horizonte a partir do qual deveria ser pensado o fundamento da razão. Nasce assim o paradigma mentalista que, antes de tudo, surge como tentativa de legitimar os princípios racionais com base nesta atitude objetivante frente aos fatos da natureza.

O fascínio que o rigor metódico-procedimental das ciências modernas causou sobre os pensadores modernos levou Kant a tomar tal atitude teórica como paradigma de validez de toda a experiência possível ${ }^{35}$. O esquema da filosofia transcendental, fincado na relação sujeito-objeto (marco do paradigma da consciência), tem como modelo essa nova atitude objetivante característica da ciência moderna. Ao universalizar esse modelo para qualquer prática do conhecimento que busca a sanção da razão, Kant traz a questão da validade para a consciência monológica: a verdade das proposições é guiada pela possibilidade de sua objetividade como conseqüência de uma relação diretamente proporcional à possibilidade da experiência possível do sujeito transcendental, logo na formalização dos objetos pela subjetividade transcendental como atividade dos "juízos sintéticos a priori”. Ou seja, a 
verdade (como confirmação da validade de uma dada afirmação) só será possível a partir de garantias objetivas da experiência que a filosofia transcendental explicita na Crítica da Razão ${ }^{36}$, colocando-a como momento de objetivação dos juízos sintéticos a priori. Em Kant, a verdade não depende da correspondência direta para com os objetos da natureza e sim dos limites e das regras que são seguidas pela consciência transcendental.

No entanto, Kant - como, de resto, o racionalismo cartesiano, o empirismo inglês e a metafísica clássica em seu conjunto - cai numa aporia que Habermas aponta como sendo o tratamento da verdade e da obejtividade de modo intrínseco. Para J. Habermas, é necessário tratar estas questões separadamente em busca de seus aspectos específicos. O que este filósofo faz é procurar não reduzir, ou simplesmente restringir, a questão das validade à objetividade da experiência possível. Nesta ótica, a idéia de objetividade é investigada a partir da reconstrução da lógica do desenvolvimento (modernização) das sociedades ocidentais ${ }^{37}$.

A compreensão da objetividade é dada no momento qm que se reconstrói a importância da categoria do trabalho ${ }^{38}$, enquanto ação instrumental do homem frente aalgho que lhe resiste continuamente ( a natureza). A partir desta compreensão, podemos ver que o trabalho tem um dupla função: i) realização de uma ação voltada para a satisfação de carências, na produção de bens diversos; ii) desencadeamento de uma atividade epistêmica relativa a sua práxis instrumental. Essa esfera de ação humana é chamada de ação instrumental. É nela que que o homem encontra algo que resiste a suas ações, algo que pode ser denominado como a natureza-em-si. Como nos lembra Durão ${ }^{39}$, esse conceito não deve ser apresentado como uma espécie de retorno à metafísica, e sim uma idéia reguladora da investigação empírica: essa idéia, segundo Habermas, promove uma dinâmica no nosso conhecimento no sentido de maior refinamento nas exposições teóricas.

A novidade deste empreendimento reside, contudo, na compreensão de uma outra esfera de real importância: a $a c ̧ a \tilde{o}$ comunicativa. Ela resgata o momento de reprodução das estruturas simbólicas que se dá no plano da interação, responsável pela realização da tríade do mundo vivido: sociedade, cultura e personalidade. Habermas vê na ação comunicativa uma esfera que não pode ser absorvida pela 
categoria do trabalho, direcionando assim suas pesquisas na explicitação dos elementos normativos geradores de relações interativas. Será com eles que se poderá ver o modo como os objetos da experiência (a objetividade) e a validade das proposições (situada na esfera das pretensões de validade da ação lingüística) serão especificadas ${ }^{40}$.

Nos dois planos de ação diferenciados por Habermas ação "instrumental" e ação "comunicativa" -, a objetividade reside no plano da ação instrumentalmente mediada, caracterizada por uma racionalidade com respeito a fins. A esfera da ação comunicativa é o lugar onde acontecem as relações interativas, lingüisticamente mediadas, entre osindivíduos de uma dada sociedade - esfera na qual Habermas explicita o principal conceito de sua vasta obra. A questão da "verdade", diferentemente do tema da objetividade da experiência, aparecerá nesta explicitação através da chamada "teoria da competência comunicativa" ou "pragmática universal".

A finalidade estabelecida no plano da ação comunicativa (o telos da comunicação, na linguagem do próprio Habermas) reside em um consenso garantido pela prática de um entendimento baseado numa argumentação livre de quaisquer forças coercitivas, a não ser aquelas estabelecidas com bases nas ofertas racionais contidas nos atos de linguagem. Na compreensão habermasiana, a verdade, sendo uma pretensão de validade, não deve ser mais abordada do ponto de vista da objetividade científica - como foi, por exemplo, com Kant, e, mais tarde, com os adeptos do positivismo lógico. Habermas sugere uma nova teoria que trate a questão da verdade ${ }^{41} \mathrm{com}$ base na idéia de um consenso racionalmente motivado (intersubjetivamnte realizado), cujo o meio específico de relização é a linguagem. Antes, porém, de abordar os problemas maiores de uma teoria discursiva da verdade, Habermas preocupa-se em esclarecer três questões prévias ${ }^{42}$ :

A primeira questão diz respeito ao sentido do verdadeiro e do falso. Em breves palavras, Habermas pretende mostrar como se realiza a idéia de verdade a partir da teoria dos atos de fala. Neste caso, a verdade seria uma pretensão de validade erguida numa dada afirmação, que reflete de modo real um estado de coisas, isto é, a verdade é uma pretensão de validade estabelecida ou vinculada pelo falante aos enunciados, através 
dos quais ele afirma algo. O importante não é tanto a afirmação feita, mas o sentido do empregado dos enunciados nas afirmações, em relação aos quais a pretensão de verdade pode ser estabelecida com ou sem razão.

A segunda questão mostra como é possível a problematização e resolução de uma dada proposição, da idéia de realização da verdade discursiva. Habermas distingue dois níveis da comunicação: i) o nível da ação comunicativa, no qual os indivíduos trocam informações "ingenuamente" aceitas, sem levantar dúvidas sobre qualquer pretensão de validade; ii) o nível discursivo, no qual os indivíduos apresentam razões em vista de um resgate de pretensões problematizadas, na busca de um restabelecimento do estado norma da comunicação. Neste sentido, uma afirmação será verdadeira quando for justificada racionalmente através de discurso específicos. Esta teoria discursiva da verdade propõe, pois, uma constatação metalingüística do sentido pragmático da pretensão de validade embutida numa afirmação posta em suspensão posta em suspensão e, por isso, levada ao plano do discurso na tentativa de toma-lo como verdadeiro ou falso.

O seu programa de uma filosofia crítica renovada a partir de uma teoria comunicativa, o pôs diante de um desafio tal qual aquele acontecido com Kant: a reformulação do programa de razão e suas implicações aos aspectos teóricos, práticos e estéticos, da razão. Não se atendo muito ao último aspecto, este filósofo demostra um interesse ao primeiromas, sobretudo, será ao segundo que irá dedicar um número grande de obras. Levando a cabo o projeto frankfurtiano da interdisciplinaridade, Habermas ao tratar da filosofia prática, dando tanto um tratamento que explicite os seus diferentes momentos, do seus aspectos procedimentais, como também "genealógico" 43 . Logo podemos concluir que os temas da ética, direito, racionalidade e modernidade, são temas interligados entre si.

\section{Uma Modernidade Intelectual Inacabada}

O projeto da modernidade de uma sociedade racionalmente emancipada, foi posto em cheque numa tradição filosófica que vai de Nietzsche, passando por Heidegger e os frankfurtianos, chegando aos descontrutivistas como Deleuze, 
Foulcault, Derrida, Lyotard e Vattimo. Tendo consciência disto, Habermas propõe-se resgatar a proposta kantiana de desenvolver uma filosofia que reconheça os limites da razão, evitando os devaneios metafísicos e que tambémprocura evitar qualquer tipo de ceticismo.

O diagnóstico empreendido pelo este filósofo alemão das "patologias" sócio-racionais das sociedades modernizadas, toma uma direção própria ao se afastar de conclusões tão dramáticas quanto àquelas empreendidas por Weber,T.-W. Adorno, M. Horkheimer, H. Marcuse, enfim, de toda esta geração da Escola de Frankfurt ${ }^{44}$. Para ele, o clima catastrófico sugerido pela perspectiva filosófica da Dialética do Esclarecimento ${ }^{45}$ representa tão somente o esgotamento do paradigma da consciência, e não o esgotamento da potencialidade emancipadora da razão como se pensou e, no caso do pósestruturalismo francês, como ainda se pensa.

A partir da apresentação dos quatro movimentos filosóficos do século XX, a saber, a fenomenologia, o estruturalismo, a filosofia analítica e o marxismo, Habermas reconstrói os impulsos mais importantes do pensar que constituem o horizonte do pensamento pós-metafísico. Esses impulsos levaram o filosofar do nosso século a assumir algumas singularidades que fizeram romper com a tradição. Relembro aqui quais foram elas: i) o "pensamento pós-metafisico" representa o momento em que a razão passa a ser apoiada em procedimentos, abandonando as reflexões privilegiadas que impõem per se as estruturas da razão que decidem sobre a racionalização do mundo dos homens e da natureza; ii) a "guinada lingüística" impõe-se como deslocamento para um novo paradigma, que tende a superar a tradição filosófica fincada no paradigma da consciência, no momento em que a compreensão da constituição da interação social e a construção do conhecimento sobre os fatos no mundo deixam de ser operações meramente fundadas numa consciência solitária e passam a ser compreendidas através das relações lingüisticamente mediadas; iii) um novo "modo de situar a razão" aparece como tentativa de compreender a racionalidade humana não mais como algo que transcende os contextos das práticas historicamente encarnadas em nossos mundos da vida; e, por último, iv) "superação do logocentrismo" que surge como tópico complementar do anterior, no qual a idéia de razão passa 
a ser compreendida se, e somente se, for reconstruída a partir de suas próprias operações, ou seja, das realizações cognitivas que estão enraizadas nas práticas pré-científicas que existem entre pessoas e coisas. A partir destes motivos, Habermas advoga uma teoria da modernidade orientada por um modelo mais "débil" de razão que não se confunde com os sentimentos de despedida da filosofia. Para ele, os motivos de uma "exoneração terapêutica", de uma "despedida heróica" ou do "despertar hermenêutico" ignoram a força do uso cognitivo da comunicação no uso de expressões lingüísticas sobre algo no mundo social, subjetivo e natural, numa época em que o dissenso é presente devido à diluição das certezas míticas, metafísicas ou religiosas (descentralização da "visão de mundo").

Habermas afirma que os enfraquecimentos da articulação transcendental do pensar e da idéia de uma "filosofia primeira" não impedem a reconstrução dos pressupostos universais da razão teórica e prática presentes no mundo vivido - onde ocorrem os processos de autoformação do indivíduo e da espécie. Por isso, o filósofo da comunicação advoga uma teoria da razão que proceda, inicialmente, interpretando os fenômenos significativos, e parte daí para uma reconstrução hipotética dos saberes pré-científicos que tornam os indivíduos competentes para gerarem configurações simbólicas essenciais para uma integração social. Para tanto, sua teoria geral da racionalidade inclui as seguintes teorias complementares: i) uma pragmáticauniversal, que se baseia na idéia de que não só a língua mas também a fala é suscetível de uma reconstrução racional em termos universais; ii) uma teoria da socialização, conduzida em termos de aquisição da competência comunicativa; iii) uma teoria dos sistemas sociais, que reconstrói as interconexões para além das articulações subjetivas ou mesmo internalizadas em contextos; iv) uma teoria da evolução, que torna possível a reconstrução das situações históricas do interprete e da interpretação.

A teoria comunicativa teve como tarefa a destranscendentalização da razão, reconstruindo os pressupostos universais do entendimento numa concepção de racionalidade corporificada na prática cotidiana da comunicação. Habermas reconstrói as condições do uso racional da linguagem no momento em que ela cumpre as pretensões de validez ofertadas nos proferimentos. Estas pretensões são estabelecidas nos 
enunciados em que os concernidos pretendem gerar um consenso entre si, de modo justo, verdadeiro e veraz. Com isso, se permite então as funções interativas, constatativas e expressivas, que são fundamentais para uma coordenação cooperativa entre indivíduos de uma dada sociedade. Os "tipos ideais" da fala, reconstruídos pela pragmática formal, constituem as condições de legitimidade das relações comunicativas voltadas ao entendimento mútuo. O diálogo é, portanto, aquele que torna possível a reconstrução da legitimidade normativa na medida em que ele se apóia na justificação de uma comunicação apoiada na livre argumentação racional sem coerção externa.

\section{Conclusão}

Mesmo nascendo no horizonte filosófico moral de Emmanuel Kant, a Razão Comunicativa abandona os fundamentos analíticos da filosofia subjetivo-transcendental em favor de uma filosofia pragmático-lingüística de pretensão pósmetafísica. Habermas procura fundamentar as noções de razão prática em princípios pragmático-universais da comunicação na qual é possível encontrar a existência de pretensões de validade específicas à argumentação prática. Essa tentativa de articular racionalmente um ponto de vista moral acontece a partir da necessidade de uma base neutra para a fundamentação das normas de ação prático-morais. Apoiado na teoria do desenvolvimento social, Habermas declara que nas sociedades pluralistas não é mais possível dar às prescrições morais uma justificação pública baseada em um ponto de vista transcendente, seja de natureza religiosa ou metafísica. Ademais, a situação de uma sociedade profanizada onde as ordens normativas têm de ser mantidas sem garantias metasociais agudiza a preocupação de se integrar o mundo da vida pluralizado, uma vez que cresce simultaneamente o risco de dissenso nos domínios do agir comunicativo desligado de autoridades sagradas e de instituições fortes. As sociedades tradicionais, onde vigoram modelos convencionais de conduta, se caracterizam pela partilha homogênea de valores, costumes e expectativas. Por experimentarem uma planificação axiológica, estas comunidades não precisavam, necessariamente, diferenciar 
em esferas autônomas o direito, a religião, a moral, a ciência, a arte e a política. Por serem mais homogêneas, os seus estatutos normativos se expressam dentro de seus sistemas de valores logo o direito se mistura às expressões estéticas, religiosas e produtivas. Por isso o direito é cantado em hinos religiosos, em expressões e recomendações familiares, em pinturas e na compreensão das relações cosmológicas. Os códigos de conduta, deste modo, estão entrelaçados num sistema simbólico orientado por uma visão substancial do cosmos. O fundamento público das normas neste tipo de comunidade segue as cosmovisões religiosas que servem como uma espécie de "dossel sagrado". A autoridade das normas reside nas compreensões cosmogônicas e cosmológicas dos grandes mitos sagrados. Nas comunidades totêmicas, por exemplo, as "alianças" que enlaçam os homens, a natureza e as divindades norteiam os fundamentos imperativos destas comunidades. Desta forma, a justificação pública das normas nas sociedades tradicionais segue um ponto de vista "cognitivo religioso", isto é, uma orientação apoiada num sistema simbólico próprio às antigas cosmovisões. Ou seja, longe de compreender uma orientação normativa guiada por um princípio imparcial ou de eqüidade, as sociedades tradicionais orientam a justificação das normas a partir de um sistema simbólico embutido em visões compartilhada intersubjetivamente.

Para Habermas, o fato de as sociedades modernas não se definirem mais num sistema de valor comum a todos, não significa que a ação orientada ao entendimento seja abandonada. Pelo contrário, para ele estas circunstâncias de diferenciação das formas de vida evocam na mesma proporção uma necessidade de se alcançar o entendimento mútuo sobre as normas de conduta. Por isso, se faz necessário o estabelecimento de princípios de justiça que se apresentem cada vez mais abstratos. Sob o ponto de vista da imparcialidade, estes princípios morais rechaçam a maximização dos interesses individuais em favor de uma articulação de interesses cada vez mais universais. É através das habilidades discursivas presentes na própria linguagem que se pode gerar um acordo argumentativamente estabelecido entre indivíduos que adotem um modo imparcial de participação na validação da norma de conduta - que ao mesmo tempo satisfaçam os interesses de todos os participantes. 


\section{Referências}

ARAÚJO, L.B.L. Religião e modernidade em Habermas. São Paulo: Loyola, 1996.

ARENDT, H. A condição humana. Rio de Janeiro: Forense Universitária, 1995.

BARBOSA, R. C., Dialética da reconciliação. Estudo sobre Habermas e Adorno. Rio de Janeiro: UAPÊ, 1996.

DURÃO, A B. A crítica de Habermas à dedução transcendental de Kant. Londrina-Passo Fundo: EdUEL/EdUPF, 1996.

FERRY, J.-M. Philosophie de la communication I: De l'antinomie de la verité à la fondation ultime de la raison.Paris: Cerf, Coll. 'Humanités', 1994.

FERRY, Luc. Filosofía Política. El derecho: lanuevaquerella de losantiguos y los modernos. Mexico: Fondo de cultura económica, 1991. (Vol. 1).

HABERMAS, J. Consciência moral e agir comunicativo. Rio de Janeiro: Tempo Brasileiro, 1989.

- Vorstudien und Ergänzugenzur Theorie dês

Kommunikativen Handelns (1984): Teoria de La acción comunicativa: complementos y estúdios previos. Madrid: Cátedra, 1989. . De l'éthique de la discussion. Paris: cerf, 1992.

Direito e democracia: entre fatos e normas. Rio de

Janeiro: Tempo Brasileiro, 1997.

- HABERMAS, Jürgen. Entrevista conla New LeftReview in: Ensayos Políticos. Barcelona, Ed. Penísula, 1994.

Brasileiro, 1990.

- Pensamento Pós-Metafísico. Rio de Janeiro: Tempo - Der philosophische Discurs der Moderne(1985): O discurso filosófico da modernidade. Lisboa, Publicações Dom Quixote, 1990.

HEIDEGGER, M. Fim da filosofia in: Conferências e escritos filosóficos. São Paulo: Abril Cultural, 1994, pp. 65-81.

HERRERO, F.X. "Razão kantiana entre o logos socrático e a pragmática transcendental”. Síntese Nova Fase, 52 (1991): 1243.

LYOTARD, J. F. A Condição Pós-moderna. Rio de Janeiro: José Olympio, 1998. 
LYOTARD, J. F. Moralidades pós-modernas. Papirus: Campinas, 1996.

McCARTHY, Thomas: Reflexiones sobre La racionalización en La teoria felá acción comunicativa" in: BERNSTEIN, Richard J. (Org.): Habermas y La modernidad. Madri: Catedra, 1994. OLIVEIRA, Manfredo Araújo. Heidegger e o fim da filosofia in: A filosofia na crise da modernidade. São Paulo: Loyola, 1989.

OLIVEIRA, Manfredo Araújo. Sobre a fundamentação. Porto Alegre: EDIPUCRS, 1993.

WITTGEINSTEIN, L Investigações filosóficas. São Paulo: Nova cultural, 1991.

\footnotetext{
1 Para uma leitura sobre a inserção do conceito de racionalização nos pensadores frankfurtianos, sobre tudo na teoria da ação comunicativa, Cf. McCARTHY, Thomas: "Reflexiones sobre laracionalizaciónen La teoria felaacción comunicativa" in: BERNSTEIN, Richard J. (Org.): Habermas y lamodernidad. Madri: Catedra, 1994.

2 Cf. FERRY, Luc. Filosofía Política. El derecho: lanuevaquerella de losantiguos y los modernos. Mexico: Fondo de cultura económica, 1991, p. 10. (Vol. 1).

${ }^{3}$ Enquano H. Arendt (cf. A condição humana. Rio de Janeiro: Forense Universitária, 1995) tem em vista as fortes orientações do pensamento clássico ao rechaçar a concepção de mundo dos modernos, os frankfurtianos procuram criticar um modelo de racionalidade como um processo dialéticonegativo, tendo em vista uma via alternativa (um outro da razão) para não recair naquilo que foi criticado (Adorno e Horkheimer) ou, ainda, na tentativa de criticar tal racionalidade buscando uma alternativa terapêtica a partir de um projeto de reconciliação entre a técnica e o potencial criativo da natureza requerido por Hebert Marcuse - indo, assim, ao encontro das intuições filosóficas de E. Bloch.

${ }^{4}$ Cf. Ibdem. p.05

${ }^{5}$ cf.. Heidegger, M. Fim da filosofia in: Conferências e escritos filosóficos. São Paulo: Abril Cultural, 1994, pp. 65-81.

${ }^{6}$ Cf OLIVEIRA, Manfredo Araújo. Heidegger e o fim da filosofia in: A filosofia na crise da modernidade. São Paulo: Loyola, 1989. pp. 127.

7 SegundoHeidegger, "o desdobramento da filosofia cada vez mais decisivamente nas ciências autonomas e, no entanto, interligadas, é o acabamento legítimo da filosofia. Na época presente a Filosofia chega ao seu estágio terminal”,. Cf. HEIDEGGER, Martin. O Fim da Filosofia, op. cit. p. 72. Já Lyotard afirma que "a função narrativa perde seus atores (functeurs), os grandes heróis, os grandes perigos, os grandes périplos e o grande objetivo. Ela se dispersa em nuvens de elementos de linguagem narrativos, mas também denotativos, prescritivos, descritivos etc., cada um
} 
veiculados consigo validades pragmáticas sui generis ", cf. LYOTARD, J. F. A Condição Pós-moderna. Rio de Janeiro: José Olympio, 1998. p. xvi

${ }^{8}$ Cf. LYOTARD, J. F. Op. Cit. p. 04.

${ }^{9}$ Conceito resgatado do $20 \mathrm{~L}$. Wittgesntein (CfInvestigações filosófica. São Paulo: Nova cultural, 1991) com "jogos de linguagem" entende-se um sistema de regras simbólicas, lingüisticamente mediados, regidos por leis que só tem sentido naquela sociedade em que se situa (o que implica que o jogo depende da manutenção total destas); e que os símbolos ali gerados, são tão somente conseqüencias (existência e sentido) do jogo em se situam. Cf. LYOTARD J. F..Ibdem. p. 15-19.

${ }^{10}$ Cf. LYOTARD, J. F. Um parceiro estranhoin: Moralidades pós-modernas. Papirus: Campinas, 1996. Pp. 117-138.

${ }^{11}$ LYOTARD, J.F. Moralidades pós-modernasOp. cit., ibdem.

${ }^{12}$ Cf. Idem, Condição pós-modernas, op. cit.,p. 32.

${ }^{13}$ Cf. Ibdem, p.116.

${ }^{14}$ Cf.ibdem, p. 117.

${ }^{15}$ Cf. ibdem p. 119.

${ }^{16} \mathrm{Cf}$. Ibdem, p.120.

17 LYOTARD, J. F.Muro, Golfo e Sistema in: Moralidades pós-modernas. Op. Cit. pp. 67-80.

18 Habermas refuta as compreensões funcionalistas do direito, mostrando com o aparecimento do direito positivo é consequência da dissolução dos dispositivos de autoridade da religião, ou outras cosmovisões religiosas e metafísicas; com isso, ele entende o direito e as instituições governamentais mecanismos estranhos aos dispositivos de coordenação social (tal como compreende o funcionalista Kelsen, que mantêm reservas da filosofia política hobbesiana). $C f$. $O$ direito como categoria de mediação social entre facticidade e validadein:Direito e democracia: entre fatos e normas. Rio de Janeiro: Tempo Brasileiro, 1997. Pp. 17 - 64.

${ }^{19}$ Dentre os quais podemos destacar as ideias de Hans Kelsen.

${ }^{20}$ Cf. LYOTARD, J. F. Moralidades pós-modernas, op. cit. p. 80.

${ }^{21}$ Cf. HABERMAS, J. "O horizonte da modernidade está se deslocando", in: Pensamento Pós-Metafísico. Rio de Janeiro: Tempo Brasileiro, 1990, pp. 11 17.

${ }^{22}$ Idem, Ibdem, p. 16.

${ }^{23}$ Cf. Ibdem, pp. 14-15; para uma análise mais exaustiva, ler na mesma obra: "Motivos de pensamento pós-metafísico", pp. 37-61.

${ }^{24}$ Ibdem, p.15.

25 Para Habermas as filosofias do nosso século caíram em limitações resultantes da ruptura com a tradição metafísica de pensamento, particulamente o cientificismo, a compreensão ontológica da linguagem, a crítica radical à razão e o produtivismo, cada qual referente a um dos motivos aqui apontados (cf. Ibdem, pp. 16-17).

${ }^{26}$ Cabe recordar que Habermas segue neste ponto a leitura empreendida em sua obra Der philosophischeDiscurs der Moderne(1985): O discurso filosófico da modernidade. Lisboa, Publicações Dom Quixote, 1990.

${ }^{27}$ Cf. HABERMAS, J. Pensamento pós-metafísico, op. cit., pp. 39-42. 
28 Cf. Sobre os diversos programas de fundamentação na história da filosofia, cf. OLIVEIRA, Manfredo Araújo. Sobre a fundamentação. Porto Alegre: EDIPUCRS, 1993.

${ }^{29}$ Representadas, por exemplo, na crítica da razão instrumental (Horkheimer e Adorno), e na teoria microfísica do poder (Foucault). Para tanto, cf. $O$ discurso filosófico da modernidade, op. cit., p.292.

${ }^{30}$ Acerca destes papéis obstinadamente mantidos pelo pensamento filosófico, cf. HABERMAS, J. "A filosofia como guardador de lugar e como interprete", in: Consciência moral e agir comunicativo. Rio de Janeiro: Tempo Brasileiro, 1989, pp. 17-35. Habermas menciona neste texto seis posições filosóficas que, na linhagem de Kant e Hegel, aferram-se a uma pretensão de razão em contraposição a três formas - terapêutica, heróica e que permite a Habermas distinguir, por exemplo, Horkheimer e Adorno de Foucault.

${ }^{31}$ HABERMAS, J. O discurso filosófico da modernidade, op. cit., p. 291.

${ }^{32}$ A propósito, cf. BARBOSA, R. C., Dialética da reconciliação. Estudo sobre Habermas e Adorno. Rio de Janeiro: UAPÊ, 1996; vide sobretudo o primeiro capitulo: "Da razão negativa 'a razão comunicativa", pp. 25-75.

33 Sobre a 'reconstrução' habermasiana e a 'fundamentação última' apeliana da razão, cf. FERRY, J.-M. Philosophie de la communication I: De l'antinomie de laverité à lafondation ultime de laraison. Paris: Cerf, Coll. 'Humanités', 1994.

34 Nas palavras de Araújo, "é precisamente pelo fato de não estar solidificada nas formas objetivas da racionalidade, por seu caráter fluido e informal, em que pese na sua expressão originária, que Habermas designa a razão comunicativa como uma 'razão fraca' (schwacheVernunft)". Cf. ARAÚJO, L.B.L. Religião e modernidade em Habermas. São Paulo: Loyola, 1996, p.65.

${ }^{35}$ Sobre isso, Cf. HERRERO, F.X. "Razão kantiana entre o logos socrático e a pragmática transcendental”. Sintese Nova Fase, 52 (1991): 12-43.

${ }^{36}$ É nesta primeira crítca, 1781, que os temas aqui elencados são tratados por Kant. O criticismo, como se sabe, não se esgota nela, sendo a Crítica da Razão Prática, de 1788, a principal referência no qual concerne ao tema da liberdade, e, conseqüentemente, da moralidade que nos ocupará brevemente nos próximos capítulos.

37 Trata-se de um problema cujo tratamento sociológico é feito por Habermas sobretudo com bases nas investigações weberianas em torno da modernoização entendida como racionalização bem como nos estudos influenciados pela teoria marxista da história. Habermas, na verdade, conjuga ambas as perspectivas através de uma dialética da razão que se processa tanto na base material das sociedades quanto em suas estruturas normativas. A referência principal, neste aspecto, é a sua obra magna de 1981 (Teoria do Ação Comunicativo).

38 Esta herança marxista, já apontada na nota anterior, é desenvolvida detalhadamente por Habermas no curso dos nos setenta, antes portanto da publicação de sua teoria da sociedade, através do projeto de Reconstrução do Materialismo Histórico (1976).

${ }^{39}$ Cf. Durão, A B. A crítica de Habermas à dedução transcendental de Kant. Londrina-Passo Fundo: EdUEL/EdUPF, 1996, pp. 9-32.

Problemata: R. Intern. Fil. v.6, n. 3(2015), p 171-197 ISSN 2236-8612 
40 Estamos nos referindo aos ensaios reunidos por Habermas em VorstudienundErgänzugenzurTheoriedesKommunikativenHandelns (1984): Teoria de laacción comunicativa: complementos y estudiosprevios. Madrid: Cátedra, 1989.

${ }^{41}$ Cf. HABERMAS, J. "Teoria de laVerdad"(1972), in: Idem, Ibdem, pp. 113-158.

42 Sobre o que segue, cf. Ibidem, pp. 113-120.

43 Para um melhor entendimento da diferenciação feita, no campo da filosofia prática, entre as ações morais, éticas e pragmáticas, como também da justificação do ponto de vista moral, recomendamos a obra a obra habermasianaDe l'éthique de ladiscussion. Paris: cerf, 1992; a para uma análise mais exaustiva do estatuto da moral e do direito, do tratamento do nascimento de suas formas modernas como também dos seus princípios procedimentais, recomendamos obra Direito e democracia: entre fatos e normas. Rio de Janeiro: Tempo Brasileiro, 1997.

44 Habermas não se afasta somente das intuições fatalísticas destes pensadores alemães como também se distancia do desconstrutivismo francês representado por ilustres pensadores como Derrida, Lyotard, Deleuze e Foucault. Para a constatação de tal,recomendamos a obra Discurso Filosófico da Modernidade. Lisboa: Publicações Dom Quixote, 1990.

45 Sugerimos a reverenciadaobra de T.-W. Adorno e M. Horkheimer, para que se possa deparar com seu programa filosófico de uma crítica substancial à razão instrumental. Cf. Dialética do Esclarecimento. Rio de Janeiro: Jorge Zahar Editor, 1991, 